
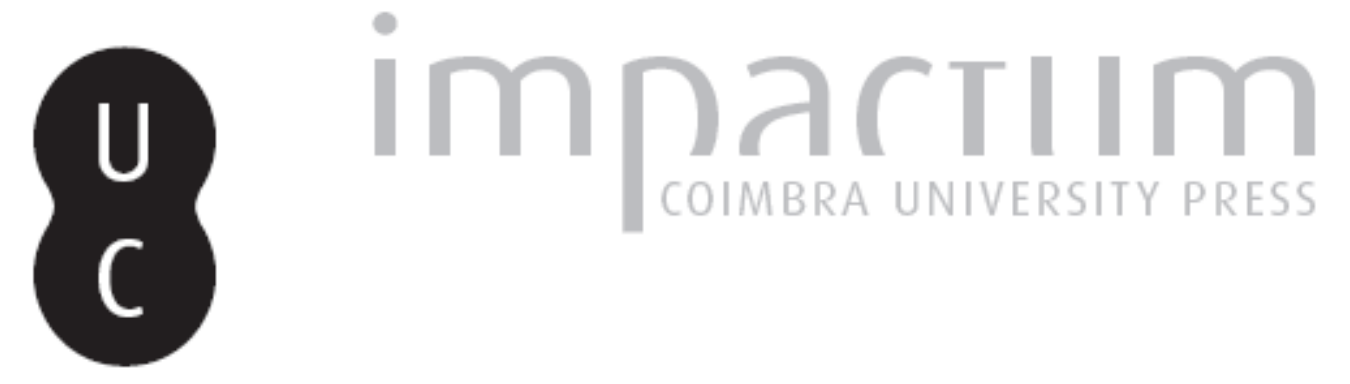

\title{
A política assistencial face aos expostos: estudo de caso do encerramento da roda dos enjeitados na Lisboa Oitocentista
}

Autor(es): $\quad$ Paulino, Joana Vieira

Publicado por: Imprensa da Universidade de Coimbra

URL persistente:

URI:http://hdl.handle.net/10316.2/43333

DOI:

DOI:https://doi.org/10.14195/1645-2259_17_9

Accessed : $\quad$ 26-Apr-2023 12:05:53

A navegação consulta e descarregamento dos títulos inseridos nas Bibliotecas Digitais UC Digitalis, UC Pombalina e UC Impactum, pressupõem a aceitação plena e sem reservas dos Termos e Condições de Uso destas Bibliotecas Digitais, disponíveis em https://digitalis.uc.pt/pt-pt/termos.

Conforme exposto nos referidos Termos e Condições de Uso, o descarregamento de títulos de acesso restrito requer uma licença válida de autorização devendo o utilizador aceder ao(s) documento(s) a partir de um endereço de IP da instituição detentora da supramencionada licença.

Ao utilizador é apenas permitido o descarregamento para uso pessoal, pelo que o emprego do(s) título(s) descarregado(s) para outro fim, designadamente comercial, carece de autorização do respetivo autor ou editor da obra.

Na medida em que todas as obras da UC Digitalis se encontram protegidas pelo Código do Direito de Autor e Direitos Conexos e demais legislação aplicável, toda a cópia, parcial ou total, deste documento, nos casos em que é legalmente admitida, deverá conter ou fazer-se acompanhar por este aviso.

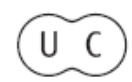




\title{
A política assistencial face aos expostos: estudo de caso do encerramento da roda dos enjeita- dos na Lisboa Oitocentista ${ }^{1}$
}

\section{Foundlings welfare: Lisbon's wheel closure in the $19^{\text {th }}$ century}

\author{
Joana Vieira Paulino \\ Instituto de História Contemporânea \\ Faculdade de Ciências Sociais e Humanas da Universidade Nova de Lisboa \\ joana_paulino40@hotmail.com
}

Texto recebido em/Text submitted on: 24/11/2016

Texto aprovado em /Text approved on: 28/04/2017

Resumo: Durante os primeiros 60 anos do século XIX as exposições nas Casas da Roda portuguesas aumentaram fortemente, dada a aceitação jurídica e legal do abandono anónimo infantil. Porém, a elevada mortalidade dos expostos, as suas más condições de vida e os custos da sua criação conduziram a debates em torno da viabilidade do modelo assistencial vigente.

A partir da década de 1860 as rodas foram gradualmente encerradas, as admissões ponderadas e controladas e generalizou-se a concessão de subsídios de lactação. Três anos mais tarde, a Santa Casa da Misericórdia de Lisboa (SCML), instituição responsável pelos expostos da capital, seguiu esta tendência.

Focando o contexto nacional, mas, sobretudo, lisboeta, reflete-se sobre o percurso das políticas assistenciais face aos expostos ao longo do século XIX, dando maior enfoque ao debate em torno da viabilidade da roda dos expostos, ao seu encerramento e à adoção do novo modelo de acolhimento.

Palavras-chave: Políticas de Proteção à Infância, Roda dos Expostos, Santa Casa da Misericórdia de Lisboa.

Abstract: During the first 60 years of the $19^{\text {th }}$ century, the number of foundlings on the Portuguese institutions increased, due to the juridical and legal acceptance of anonymous abandonment. The high mortality rate of these children, their living conditions and the high costs they represented led to debates considering the wheel's viability and a change in the welfare policy towards the abandoned children.

From the 1860's, the wheels were gradually closed, admissions were restricted and more allowances of lactation were given. Three years later, Santa Casa da Misericórdia de Lisboa (SCML), responsible for the foundlings of the Portuguese capital, followed this trend.

1 Este estudo resulta de uma investigação em curso no âmbito do Doutoramento em História, especialização em História Contemporânea, na FCSH-UNL, com o título $O$ abandono infantil em Lisboa, antes e depois da extinção da roda dos expostos (1850-1910). Conta com o financiamento da Fundação para a Ciência e Tecnologia através de uma Bolsa de Doutoramento (Ref.: SFRH/BD/112019/2015). 
Considering national, but, mainly, Lisbon's context, this study aims to reflect about the steps of foundlings welfare policy during the $19^{\text {th }}$ century, particularly, focusing on the debates towards the wheel, it's closure and the adoption of another admission model.

Keywords: Child Welfare, Wheel of Foundlings, Santa Casa da Misericórdia of Lisbon.

"A questão dos expostos, entre todas aquelas de que se ocupa a beneficência pública, é certamente uma das mais sérias e das mais árduas de resolver; nada é bom absolutamente, tudo é relativo, e varia segundo o ponto de vista e princípio em que cada um se coloca" (Rio Maior 1866: 1-2).

\section{Introdução}

Desde 1783, por circular da Intendência Geral da Polícia, generalizaram-se as rodas dos expostos a todos os centros administrativos do reino. $\mathrm{O}$ abandono anónimo infantil constituía uma prática legal, à semelhança de outros Estados europeus, com destaque para o Sul católico, nomeadamente, Espanha, França e Itália ${ }^{2}$. Perante este panorama, ao longo do século XIX, as exposições aumentaram dramaticamente, acompanhadas pela elevada mortalidade dos menores entregues nestas instituições, bem como pelas suas más condições de vida e pela enorme despesa que a sua criação representava.

A partir de meados do século, as autoridades estatais e institucionais, intelectuais e políticos, iniciaram debates em torno do encerramento da roda dos expostos e da aplicação de um novo modelo assistencial e de acolhimento da infância abandonada. A administração da Santa Casa da Misericórdia de Lisboa (SCML), responsável pela criação dos expostos da capital, também expressou o seu posicionamento relativamente a este assunto público.

A promulgação do decreto de 1867 representou o corolário máximo do descontentamento face à hecatombe do abandono anónimo infantil. Apesar de ter sido revogado após pouco tempo, as medidas que propunha foram aplicadas um pouco por todo o país - as admissões passaram a ser controladas e ponderadas, os expositores tinham de se identificar e justificar o seu ato, os hospícios substituíram as rodas dos expostos e generalizou-se a concessão de subsídios de lactação. Foi em 1870 que a SCML encerrou a sua roda e adotou, localmente, o novo modelo de admissão.

O presente estudo visa analisar a evolução da política assistencial portuguesa face aos expostos ao longo do século XIX. Embora se inicie em 1783, com a

2 Sobre o abandono infantil em Espanha vejam-se os estudos de Pérez Moreda (1996 (este último focando toda a Península Ibérica), 2005) e Revuelta Eugercios (2011), sobre França leia-se Fuchs (1984) e Jablonka (2010) e, por fim, relativamente a Itália, destaquem-se as investigações de Hunecke (1985) e Kertzer (1993). 
generalização do abandono anónimo e, com ele, das rodas dos expostos, o nosso maior enfoque será a partir de meados de Oitocentos, altura em que o debate em torno do encerramento deste mecanismo se intensifica. Quais foram as críticas apresentadas? Que soluções foram propostas para um novo modelo? Como é que o poder político respondeu aos apelos de mudança e atuou?

É nosso objetivo principal, e partindo do panorama nacional, circunscrever à realidade lisboeta. Como se posicionou a SCML no debate em torno da viabilidade da roda dos expostos? Como respondeu ao decretado pelo poder central? Como se processou o encerramento da roda na capital e a aplicação do novo modelo 3 ?

Para persecução do objetivo delineado, no que concerne ao contexto português, recorreu-se aos estudos historiográficos feitos até ao momento, à produção legislativa nacional, debates parlamentares, imprensa e a opúsculos de médicos e intelectuais. De forma a particularizar a realidade da capital, foi da maior importância a documentação contida no Arquivo Histórico da Santa Casa da Misericórdia de Lisboa, sobretudo as atas da mesa administrativa e os seus relatórios anuais.

\section{O modelo assistencial face aos expostos da primeira metade do século XIX}

Desde as Ordenações Manuelinas (1521) nas cidades, vilas ou lugares onde não existissem hospitais ou albergarias que criassem os expostos, a sua tutela recaia sobre as câmaras municipais. $\mathrm{O}$ financiamento da sua criação era feito à custa dos bens destas últimas e, quando insuficientes, recorria-se aos contribuintes pelo lançamento de fintas. Algumas misericórdias, a título voluntário, administravam a criação destes menores, sendo os custos suportados pelos municípios. Foi o que aconteceu no caso das cidades do Porto, de Coimbra e, no que diz respeito ao presente estudo, da cidade de Lisboa. Por contrato celebrado em 1635, a Misericórdia da capital passou a administrar a criação dos expostos (Sá 1992: 78).

3 Não existem, até à data, estudos aprofundados sobre o abandono infantil na Lisboa Oitocentista. Não obstante, são frutíferas as investigações sobre esta prática noutras regiões do país. Destaque-se, a título de exemplo, os estudos sobre Alenquer (Reis 1993), Porto (Sá 1995), Viana do Castelo (Fonte 2004), Évora (Abreu 2005), Torres Novas (Cubeiro 2011), Lourinhã e Torres Vedras (Antunes 2015) ou Coimbra (Lopes 2013).

A referida lacuna justifica, em parte, a nossa opção por esta investigação. Some-se, por um lado, o facto de Lisboa ser a maior cidade portuguesa, com uma dimensão ímpar no contexto nacional. Na segunda metade do século XIX, atravessava um período de crescimento populacional e espacial (muito motivado por movimentos migratórios), ao mesmo tempo que a sua dinâmica urbana, económica e social se alterava. Por outro lado, a capital constituía uma exceção no quadro assistencial, sendo que esta Misericórdia foi, como veremos, a única a continuar a gerir a criação dos expostos após 1836, ao mesmo tempo que a sua administração era eleita pelo governo. 
Em 1783, Pina Manique (1733-1805), chefe da Intendência Geral da Polícia, decretou que todos os centros administrativos deviam ter uma instituição de assistência aos expostos, com rodas ${ }^{4}$. Generalizou, assim, este mecanismo giratório que permitia abandonar a criança a qualquer hora do dia sem que o expositor fosse visto por quem se encontrava do outro lado da mesma. Previa-se a localização das Casas da Roda em sítios estrategicamente discretos, de fácil acesso e anunciando-se publicamente a sua morada (Ordem Circular da Intendência Geral da Polícia, de 24 de Maio de 1783: 150-152). O abandono passou-se a reger pelo silêncio, segredo e anonimato, não se penalizando ou tentando identificar os expositores 5 .

Contudo, a ordem de proliferação destas instituições não foi cumprida em todo o reino. Na repreensão feita por circular de 1800, criticava-se

"que todos os Juízes de Fora, e Ordinários da sua Comarca, de uns tempos a esta parte se acham esquecidos de suas obrigações (...) que recomendam o estabelecimento das Rodas dos Enjeitados, e a criação destes" (Ofício da Intendência da Polícia, de 5 de Junho de 1800: 152).

O modelo assistencial do início do século XIX apresentava ainda outros problemas estruturais, generalizados a todo o país. As misericórdias tinham elevados encargos com a administração dos expostos, pois nem sempre as câmaras municipais cumpriam a sua função. A falta de amas era constante, bem como os seus baixos e incertos salários. $\mathrm{O}$ abandono em rodas vizinhas proliferava tentando-se, através desta via, evitar o aumento dos impostos no concelho de onde a criança exposta era originária (Cubeiro 2011: 10).

Foi perante esta conjuntura que, por decreto de 19 de Setembro de 1836, Passos Manuel (1801-1862) uniformizou o serviço de assistência aos expostos. Deixou de existir a dualidade misericórdias/câmaras municipais, para a responsabilidade passar a recair, unicamente, nestas últimas. Cabia às juntas gerais de distrito determinar as contribuições municipais e a localização das rodas dos expostos. Impôs-se como exceção o caso lisboeta, onde a SCML

4 A roda era um cilindro de madeira oco, que girava sobre um eixo, colocada na janela de um edifício e tendo uma única abertura. A criança era posta no interior da roda e o expositor devia tocar numa campainha, situada na parede, de forma a avisar a rodeira. Esta, no interior do edifício, rodava o cilindro, recolhia a criança e fornecia-lhe os primeiros cuidados de saúde (Sá 1992: 79).

5 A generalização das Casas da Roda em Portugal no final do século XVIII surgiu com base numa política populacionista, acompanhando a tendência de outros Estados da Europa católica do Sul. Pretendia-se, desta forma, combater o elevado infanticídio, o aborto e o abandono de crianças em locais que não permitiam a sua salvação atempada, privando o país de indivíduos úteis para o seu progresso (Fonte 2004: 133). Segundo Teodoro da Fonte, antes de 1783 já existiam Casas da Roda nas cidades e vilas mais importantes, sobretudo, em associação às respetivas Misericórdias. Contudo, temendo um aumento excessivo do abandono infantil, muitos concelhos ainda não tinham procedido à sua implementação. Foi apenas a partir de 1783 que se oficializou a roda enquanto mecanismo de exposição anónima infantil (Fonte 2004: 134). 
continuou a administrar a criação dos abandonados (Decreto de 19 de Setembro de 1836: 8$)^{6}$.

Não obstante a reforma de Passos Manuel, os problemas referidos anteriormente persistiram, sendo acompanhados por um grande aumento do abandono infantil. No caso dos expostos de Lisboa, a SCML reconhecia que a crescente aglomeração de menores na instituição afetava a sua qualidade de vida. No seu relatório de 1836, refere-se a falta de condições da Real Casa dos Expostos de Lisboa - por vezes, dormiam três a cinco crianças na mesma cama, estando quase todas afetadas por inflamações nos olhos ou com sarna. O espaço era pouco limpo, com falta de ar puro e sem zonas de recreio. É ainda referida a necessidade de vestuário, sobretudo, durante o Inverno, "de que tanto careciam, para a conservação da sua saúde” (AHSCML, Relatório... 1836: 2).

A concentração de expostos nesta instituição era agravada pela falta de amas. $\mathrm{Na}$ mesma fonte, refere-se que nela chegaram a estar reunidos 152 abandonados, havendo apenas 31 amas internas para os aleitar. O reduzido número destas funcionárias era justificado pelo atraso de cinco meses de salários. A falta de pagamento estendia-se também às amas externas não havendo, desta forma, quem criasse estes menores, aumentando a população na Real Casa dos Expostos de Lisboa e, consequentemente, "seguindo-se (...) uma espantosa e horrível mortandade dos inocentes" (AHSCML, Relatório... 1836: 2). A necessidade de amas prolongar-se-ia por toda a centúria, pelo que a SCML estava constantemente a pedir aos párocos para "que promovam a concorrência de amas de leite, que venham a esta Santa Casa buscar expostos, na certeza de pronto pagamento" (AHSCML, Ata ... n. ${ }^{\circ}$ 2, fl. 5-5v) ${ }^{7}$.

$\mathrm{O}$ abandono infantil em rodas vizinhas também persistiu. A capital era constantemente confrontada com a afluência de abandonados de fora da cidade, prática que a SCML considerava abusiva. Neste sentido, pressionava o governo para fazer cumprir a generalização das rodas dos expostos e para castigar os administradores dos outros concelhos, impondo-lhes penas e, em casos de con-

6 Em 1834, por falta de irmãos eleitores, a mesa da SCML solicitou ao governo que nomeasse os seus membros. Apesar de se pretender que esta situação fosse provisória, acabou por se prolongar no tempo. Tendo sido reformado o seu compromisso em 1851, a SCML passou a divergir das suas pares. A Irmandade deixou de integrar a sua administração, sendo a mesa administrativa e o provedor eleitos por nomeação régia. Desta forma, a SCML era, então, uma "misericórdia" apenas de nome, pois a sua orgânica já não se assemelhava à deste tipo de instituições (Lopes 2013: 20-21).

A instituição chegou mesmo a solicitar um empréstimo para pagamento dos valores em atraso dos salários das amas procurando, por esta via, atrair um maior número de funcionárias (AHSCML, Correspondência, fl. 1). Na década de 1850, existiam entre 25 a 40 amas internas na Real Casa dos Expostos de Lisboa. Não obstante, considerava-se que a probabilidade de sobrevivência dos menores na instituição era bastante baixa, preferindo-se o seu envio para amas residentes em zonas rurais, sobretudo dos concelhos da Figueira da Foz, Ourém e Batalha, "onde elas [as crianças] se identificam com as famílias das amas, e raras vezes dali regressam para a casa. (...) Muitos não recebem instrução alguma e são simples trabalhadores como os seus irmãos colaços; mas adquirem uma família” (AHSCML, Relatório... 1862: 9). 
tinuidade, obrigando-os a pagar a criação destes menores. Este abuso era cometido, sobretudo, pelos concelhos próximos de Lisboa, como o caso ocorrido em $1853 \mathrm{em}$

"que consta a esta mesa haver em Torres Vedras uma mulher paga e encarregada pela Misericórdia da mesma Vila de indagar aonde existem puérperas em circunstâncias de expor os filhos, para, mediante a quantia de 1200 reis por cada um, os trazer à Roda desta Cidade" (AHSCML, Ata ... n.o 2, fl.19v).

Reconhecendo as enormes proporções da prática de exposição, os abusos cometidos por outros concelhos e visando diminuir o abandono infantil, a Misericórdia de Lisboa procurou responsabilizar os pais dos abandonados, solicitando ao Patriarca que recomendasse aos párocos que, no confessionário e nas práticas da Quaresma,

"fizessem sentir o grande pecado que cometiam os pais que enjeitavam filhos, tendo meios de criá-los e permitisse a colocação, em todas as freguesias, de caixas, que em quaisquer pessoas caritativas lançassem esmolas para os enjeitados, e mesmo os pais, que indevidamente tivessem enjeitado os filhos, depositassem a indemnização que entendessem ser por isso devida à Santa Casa" (AHSCML, Correspondência, fl. 2).

\section{Os debates em torno do encerramento da roda dos expostos}

Perante a conjuntura apresentada, agudizou-se o sentimento face às crueldades vividas pelos expostos, ao mesmo tempo que a prática do abandono infantil proliferava. Vários foram aqueles que começaram a questionar a viabilidade deste mecanismo, nomeadamente, políticos, médicos e outros intelectuais, apresentando propostas de um novo modelo assistencial no que concerne ao abandono infantil.

No contexto do seu exílio em Paris, o médico Francisco de Assis e Sousa Vaz (1797-1870), pôde observar os resultados da passagem da roda dos expostos enquanto mecanismo de abandono anónimo para a roda vigiada, o que o levou a concluir que a primeira alimentava a prática da exposição. A forma como estes menores eram tratados até chegarem às Casas da Roda, nestas instituições e a cargo das amas era considerada, pelo médico, uma barbárie, um verdadeiro infanticídio (Vaz 1843: 56).

Outro médico que questionou a viabilidade da roda dos expostos foi Thomaz de Carvalho (1819-1897). Enquanto encarregado da direção da enfermaria de Santa Bárbara do Hospital de São José, em Lisboa, presenciou e concluiu que, das grávidas que aí tiveram os seus filhos, muito poucas os levaram consigo à saída, sendo a maioria destes enviados para a Real Casa dos Expostos da SCML, 
sobretudo, devido à miséria ou vergonha da mãe. Assim, Thomaz de Carvalho considerava que a roda era um "açougue de crianças", que incentivava à desmoralização, ao vício e que punha fim ao conceito tradicional de família (Carvalho 1853: 557). Neste contexto, propôs, tal como já havia sido aplicado no mesmo hospital, que "as mulheres conservassem os filhos durante oito a dez dias, que é o tempo que elas demoram no hospital depois do parto", desenvolvendo, desta forma, laços de afeto e dificultando a separação (Carvalho 1853: 568). A esta medida somava a necessidade de uma estrutura combinada entre as admissões ponderadas e a concessão de subsídios de lactação.

Os deputados António Luiz de Souza Henriques Secco (1822-1892) e José Moraes Pinto d'Almeida (s.d.) também consideravam o abandono infantil "um grande cancro que corroí as entranhas das sociedades civis" (AHAR, Câmara dos Senhores Deputados, 1855 - n. $\left.{ }^{\circ} 13: 226\right)$. Em 1855, apresentaram à Câmara dos Senhores Deputados um projeto-lei propondo o encerramento das rodas dos expostos e a sua substituição por hospícios nas capitais de distrito. Consideravam ainda uma mais-valia a atribuição de subsídios de lactação, cujos efeitos positivos já eram conhecidos por todo o país (AHAR, Câmara dos Senhores Deputados, 1855 - n. ${ }^{\circ} 13: 225-228$ ).

No seio administrativo da SCML, o adjunto do provedor da instituição, António Figueira e Sousa (1836-1891), $4 .^{\circ}$ Conde e $1 .^{\circ}$ Marquês de Rio Maior, redigiu vários opúsculos sobre o forte aumento das exposições e as soluções a adotar. Evidenciou a falta de verba da instituição, criticando que a Câmara Municipal de Lisboa não cumpria a sua responsabilidade para com a criação dos expostos e no auxílio às mães pela concessão de subsídios de lactação. Apontava ainda que as autoridades administrativas não levavam a cabo as devidas intimações parentais. Cria na existêbcia de uma estrutura combinada, conciliando os subsídios com a fiscalização, pois "fechada a roda simplesmente, a exposição, em lugar de ser feita em $S$. Roque, há de exercer-se às portas das igrejas, nas ruas ou nas praças públicas" (Rio Maior 1869: 35).

Grosso modo, a solução apresentada pelos médicos, deputados e intelectuais referidos anteriormente não passava pelo encerramento da roda enquanto instituição - a Casa da Roda -, pois como afirmava o Conde de Rio Maior, não existia em Portugal uma caridade privada (Rio Maior 1866: VII). Propunham, sim, o encerramento da roda enquanto mecanismo giratório de abandono anónimo. A instituição deveria persistir, mas alterando-se o modelo de admissão e criando-se uma estrutura combinada, assente em três pilares - admissões ponderadas e controladas; policiamento das zonas públicas e dos espaços em torno das instituições; e, por fim, generalização dos subsídios de lactação, permitindo às mães manter os seus filhos.

Por contraponto ao posicionamento contra a roda dos expostos, impõe-se um seu apoiante, o estudante de medicina Manuel Caetano da Cunha (s.d.). Na 
sua tese final do curso médico-cirúrgico defendeu que a roda permitia a sobrevivência de muitas crianças, pois era uma alternativa ao infanticídio e ao aborto. Comparava este mecanismo "como a mão caridosa da sociedade com que encobre a vergonha de uma fragilidade honesta, ou evita uma grande miséria que arrojaria ao túmulo a mãe e filhinho conjuntamente" (Cunha 1873: 39). Apesar de não concordar com a supressão das rodas dos expostos, tinha consciência da necessidade de reforma do modelo vigente, sobretudo, nos setores da alimentação e educação.

Efetivamente, no final da década de 1850, algumas câmaras municipais começaram a revelar uma mudança de atitude face à legalidade do abandono anónimo nas rodas dos expostos. Tal é-nos transmitido pelo discurso do deputado António Vidal Silveira (1808-1879), que evidencia uma maior vigilância, fiscalização e tentativa de responsabilização parental da parte das autoridades municipais - "em vários concelhos os administradores por meios honestos e sem devassar o seio das famílias, sem vexar nem envergonhar pessoas honestas, faziam educar os filhos ilegítimos pelos seus pais ou mães" (AHAR, Câmara dos Senhores Deputados, 1858 - n. ${ }^{\circ}$ 2: 45). Em Lisboa, as atas da SCML também faziam transparecer esta tendência, apoiando-se a instituição nas autoridades policiais para descobrir quem eram os expositores e se a sua pobreza era comprovada (AHSCML, Ata ... n. ${ }^{\circ}$ 3, fl. 20v).

O combate às rodas oficializou-se em 1862, com a intervenção do governo no debate público pela nomeação de uma comissão para estudar o problema do serviço de expostos. Esta considerava que a roda era uma instituição moderna, mas que, no entanto, as suas competências foram alargadas, "tornando-se num convite público aos pais que quisessem desembaraçar-se dos filhos", gerando abusos provocados, sobretudo, pela miséria ([anexo ao] Decreto de 21 de Novembro 1867: 892). Assim, a comissão tinha como função formular soluções para uma diminuição das exposições, dos encargos que representava a criação destes menores, bem como para a sua elevada mortalidade (sem que tal tivesse, por contraponto, um aumento dos infanticídios).

"No ano económico de 1861/62 haviam sido enjeitadas em Portugal 16.429 crianças, no ano seguinte 15.536 , a que se acrescentavam os 37.167 expostos com menos de sete anos. Os abandonos correspondiam a um por cada oito nascimentos e a despesa nacional com o sistema da roda ultrapassava os 390 milhões de réis, sendo $70 \%$ pagos pelos municípios e 30\% pela Misericórdia de Lisboa, distrito onde os expostos atingiram 32\% do total” (Lopes 2016: 4).

Foram propostas três soluções estruturantes para a nova política, que consideravam não poder ser fundada numa rutura violenta, mas sim numa transição: 
1. Substituição das rodas dos expostos por hospícios distritais de admissão justificada, ponderada e controlada ${ }^{8}$.

2. Reforço da declaração de gravidez de mulheres não recatadas 9 .

3. Generalização da concessão de subsídios de lactação mediante pobreza comprovada. Este apoio não teria os resultados desejados se não houvesse uma restrição das exposições ([anexo ao] Decreto de 21 de Novembro 1867: 890-899) ${ }^{10}$.

No relatório da SCML do mesmo ano é referido que "a nossa voz e os clamores de todas as juntas gerais de distrito foram enfim escutados, e que o governo de Sua Majestade dá presentemente a tão grave questão a importância que ela tem". Caberia à mesa administrativa da SCML "prestar à comissão (... todos os esclarecimentos de que possa dispor, como também apresentar algumas reflexões sobre a matéria, sugeridas pela apreciação dos factos que ela diariamente presenceia" (AHSCML, Relatório... 1862: 4).

A SCML cria que as elevadas exposições não se deviam à miséria, mas sim à própria roda dos expostos "que não só promove cada vez mais o abandono das crianças, mas até parece desculpá-lo, incutindo a ideia de que em semelhante ato nada há de repreensível, visto que a sociedade o aceita com indiferença" (AHSCML, Relatório... 1862: 4). Apoiava o encerramento deste mecanismo, recebendo-se os menores apenas durante o dia, acompanhados de um atestado passado pela autoridade administrativa que confirmava se a criança era ilegítima, de mãe residente em Lisboa e que não a podia manter consigo. Só mediante esta confirmação do poder local, poderia dar entrada na instituição (AHSCML, Relatório... 1862: 5).

Por sua vez, o socorro às mães pobres pela concessão de subsídios de lactação, era perspetivado como uma prática aceite e recomendada, uma consequência necessária do encerramento da roda dos expostos. Não deveriam, contudo, coexistir os dois sistemas - roda e lactações -, como até então vigorava, pois dessa forma não diminuíam as exposições (AHSCML, Relatório... 1862: 5).

8 O sistema de controlo anterior à admissão foi colocado em prática no distrito de Lisboa, excluindo na capital, demonstrando bons resultados. Por sua vez, desde 1865, a investigação posterior à admissão foi aplicada no Porto. A comissão inclinava-se para o primeiro modelo, seguido pelo distrito de Lisboa, que considerava ser mais fácil e rigoroso ([anexo ao] Decreto de 21 de Novembro de 1867: 896).

9 Esta medida remonta às Ordenações Filipinas, tendo sido reforçada por Alvará de 1806. Contudo, segundo Maria Antónia Lopes, só começou a ser aplicada de forma consistente pelas autoridades em meados do século XIX (Lopes 2016: 1-2).

10 Os subsídios de lactação, instituídos na segunda metade do século XIX, consistiam em prestações pagas às mães solteiras durante os meses de amamentação da criança, altura em que necessitavam de se alimentar melhor e em que tinham a sua capacidade laboral reduzida, permitindo-lhes assim pagar o serviço de uma ama. Na SCML a concessão deste tipo de auxílios aumentou a partir da década de 1850, sendo concedidos não só a mães, mas também a pais e outras pessoas do agregado familiar. 
Para além das medidas conducentes ao fim do abandono anónimo e à concessão de pensões, a SCML considerava imprescindível aliar uma estrita fiscalização da Real Casa dos Expostos de Lisboa, entregando esta função a pessoas habilitadas, nomeadamente, às autoridades administrativas locais. Reconhecendo a exigência deste tipo de função, contrapunha com a necessidade de aumento do salário destes funcionários (AHSCML, Relatório ... 1862: 5).

Acompanhando a tendência nacional de combate à exposição, a SCML começou a aplicar medidas particulares que considerou bem-sucedidas. Até ao início da década de 60, oferecia-se às parturientes da enfermaria de Santa Bárbara a condução da criança para a Real Casa dos Expostos de Lisboa, por conta do hospital, caso assim o quisessem. A partir de 1862, estas passaram a ser obrigadas a amamentar os seus filhos, levando-os consigo após o internamento. "Algumas, quando saem, efetuam provavelmente o abandono, mas outras haverá que já não enjeitem o filho começando a criar, e sobretudo cessou o escândalo de ser a exposição promovida por um estabelecimento de beneficência pública" (AHSCML, Relatório... 1863: 5).

\section{O gradual encerramento das rodas dos expostos e o fim (legal) do abandono anónimo}

As medidas propostas pela comissão (e defendidas pela Misericórdia de Lisboa) viriam a ganhar forma no decreto de 21 de Novembro de 1867, que aboliu o caráter legal do abandono anónimo em Portugal e, com ele, as rodas dos expostos. A ideia central passava pela responsabilização parental ou de outros familiares da criança.

Em linhas gerais, as rodas dos expostos foram substituídas por hospícios, cabendo às juntas gerais de distrito designar as localidades do seu estabelecimento. Os hospícios dividiam-se em quatro secções: crianças expostas, abandonadas e indigentes; criação paga pelos pais ou outro parente; creches; e, enfermarias de maternidade. Quanto às primeiras, o nosso objeto de estudo, determinou-se recolher crianças: expostas em locais públicos e enviadas pela autoridade administrativa ou pela polícia; cujos pais desapareceram; filhas de pobres, presos, condenados a prisão ou degredo, com doença grave ou idade avançada; órfãs desamparadas; e, por fim, gémeas, tendo obrigatoriamente a mãe de criar um dos filhos (Decreto de 21 de Novembro de 1867: 880-883).

Relativamente às mulheres grávidas recatadas, manteve-se a possibilidade de entrega confidencial dos filhos ilegítimos, durante o período de lactação. Os menores de pais incógnitos podiam ainda ser levados para a instituição por pessoas estranhas, ficando o expositor civil e criminalmente responsável pelas declarações prestadas (Decreto de 21 de Novembro de 1867: 883). 
Já os subsídios de lactação, concedidos a mulheres desamparadas ou pobres, deviam ser requeridos pela pessoa interessada, cabendo às juntas gerais de distrito determinar as pensões a ser concedidas (Decreto de 21 de Novembro de 1867: 884).

Por fim, refira-se que, no que diz respeito à cidade de Lisboa, nomeadamente, à Real Casa dos Expostos da sua misericórdia, o decreto de 1867 determinou que "a supressão porém da roda deste estabelecimento dependerá de ulterior decreto do governo" (Decreto de 21 de Novembro de 1867: 885).

O decreto de 1867 foi revogado a 14 de Janeiro do ano seguinte, no contexto da Janeirinha, "não podendo por isso subsistir aquele regulamento, até porque estão as suas prescrições em desacordo com a legislação administrativa e penal vigente" (Decreto de 14 de Janeiro de 1868: 92). Porém, dada a insustentabilidade de manutenção do modelo assistencial vigente, as juntas gerais de distrito iniciaram a reestruturação um pouco por todo o país, aplicando as medidas propostas. Assim,

"a supressão das Rodas foi gradual: em Aveiro, Porto Leiria e concelhos rurais de Lisboa ainda na década de 60, (...) em Coimbra em 1872, em Évora em 1873, em Viseu em 1874 ... Portugal, uma vez mais, não está isolado. O movimento de extinção das Rodas na Europa situa-se entre 1850 e 1880” (Lopes 2002: 17).

$\mathrm{Na}$ capital, o abandono anónimo crescia, em parte, dado o encerramento de outras rodas dos expostos do reino, sobretudo, das mais próximas de Lisboa. No ano económico de 1850-1851 a Real Casa dos Expostos de Lisboa recebeu 2401 crianças abandonadas. Ano após ano, este valor cresceu, chegando aos 2901 menores em 1869-1870 (AHSCML, Relatório... 1871: 3).

Em Agosto de 1870 uma nova mesa administrativa tomou posse na SCML. Numa consulta, criticava a exposição de menores vindos de outros concelhos, a entrada de crianças crescidas na roda dos expostos e, ainda, a possibilidade de abandono a qualquer hora do dia. Propunha que a roda, posicionada na fachada da instituição, virada para a rua e de fácil acesso, transitasse para o seu interior. Colocava ainda a hipótese de restrição dos abandonos ao período diurno, ficando no local de receção um empregado, responsável por evitar a exposição de crianças crescidas e por apontar as declarações das recoveiras, nomeadamente, possíveis filiações (SCML 1998:125).

As medidas anteriores foram autorizadas por portaria de 13 de Setembro e a roda dos expostos da capital viria a ser encerrada a 1 de Dezembro de 1870 findando, com a sua supressão, a legalidade do abandono anónimo infantil em Lisboa. A mudança foi levada a cabo "sem quase contratempos" (AHSCML, Relatório.... 1871: 3). Três dias depois, foram aprovadas as instruções regulamentares para a vigilância e policiamento em torno e na instituição. A admissão 
de crianças passou a ser feita durante o dia, numa sala específica para este processo onde se encontrava o fiscal da roda, cargo instituído pelas referidas instruções. Este funcionário redigia o registo de entrada do menor, fazia o inquérito às recoveiras ou outro apresentante, colocava o colar provisório no novo tutelado e entregava-o à rodeira, que lhe fornecia os primeiros cuidados ao entrar na instituição (SCML 1998: 125).

A notícia sintética publicada no Diário de Notícias relativa a este acontecimento foi remetida para a segunda página do jornal. $\mathrm{O}$ que, na realidade, faz ressaltar é uma manifestação de desagrado pelo encerramento da roda dos expostos, materializada no relato de um caso de infanticídio:

"ontem apareceu uma criança recém-nascida exposta à porta da escada n. ${ }^{\circ} 129$ da rua da Atalaia, [sic] lançado ali, já de dia, o cadáver. Estava de mãos postas e amortalhado nuns trapos-brancos; era muito claro, e não apresentava sinais de violência. A autoridade fez levantar os autos respectivos, e mandou remover o cadáver para se lhe dar sepultura" (Diário de Notícias 1870).

Relativamente a este tipo de situações, a SCML pretendia

"investigar as causas dos abandonos, examinando o direito com que eles se praticavam e acudindo eficazmente com o subsídio às mães, quando a miséria os legitimasse. ( ... ) O escândalo da exposição pública no largo de S. Roque tinha cessado.” (AHSCML, Relatório... 1871: 7).

Porém, nesta fase inicial, nem sempre as investigações para identificação parental foram frutíferas. Frequentemente, as recoveiras prestavam falsas declarações quanto à legitimidade das crianças, filiação e residência dos pais. Chegavam mesmo a levar para a SCML abandonados de fora da capital. Devido a estes abusos, a instituição passou a exigir às recoveiras um documento comprovativo da sua identidade, responsabilizando-as pelas declarações prestadas (AHSCML, Relatório... 1871: 7).

Após um inquérito feito às mães, a SCML concluiu que o motivo subjacente a muitos dos abandonos não residia no vício ou na miséria, mas sim nos embaraços maternos durante o período de lactação. Como tal, visando ainda contrariar o elevado abandono e apelando à responsabilização parental, começou por não estabelecer um regulamento para a concessão dos subsídios, mas apenas breves instruções. Estes poderiam ser atribuídos a: crianças reclamadas no período de um ano; filhos de pais indigentes gémeos menores de um ano; crianças cuja mãe tinha falecido durante a lactação e o pai já não existia ou estivesse impossibilitado de pagar a uma ama; filhos de pais pobres cuja mãe tinha sido abandonada pelo marido ou cujo pai não conseguia sustentar a sua criação; menores cujo pai estivesse preso, sendo a mãe pobre; e, por fim, filhos de mães pobres estando 
o pai degredado. Era-lhes concedido mensalmente $1 \$ 600$ réis pelo peródo de pum ano, tendo ainda acesso a cuidados médicos e farmacêuticos domiciliários (AHSCML, Ata ... n. ${ }^{\circ}$ 7, fl. 124; Relatório... 1871: 8 e 11).

Assim, o encerramento da roda dos expostos fez diminuir quase de imediato o número de abandonos na Real Casa dos Expostos de Lisboa, os quais passaram a representar apenas cerca de $10 \%$ do valor médio do período anterior. No ano económico de 1871-1872 foram deixadas na instituição 780 crianças, valor que decresce até ao final do século, alcançando os 260 menores em 1899-1900 (AHSCML, Relatório... 1870-1900).

Não obstante, na década de 1870 , a SCML criticava que o número de expostos se mantinha elevado. Apesar das inquirições no ato de admissão, tudo apontava para a continuidade do abandono de crianças procedentes dos concelhos limítrofes a Lisboa. Reconhecendo a dificuldade em averiguar a veracidade desta teoria, em 1871, a instituição regulamentou que as recoveiras tinham de apresentar um comprovativo de residência das mães na capital nos nove meses antecedentes ao parto, de forma a poderem concorrer à admissão (AHSCML, Relatório... 1871: 8).

Para incentivar a recuperação parental, em Fevereiro de 1872, a mesa administrativa da Misericórdia de Lisboa decidiu oferecer às mães que recuperassem os seus filhos (entre um e dois anos de idade), entrados desde o momento do encerramento da roda dos expostos, a mensalidade de $1 \$ 000$ réis pelo período de um ano. Alguns meses mais tarde, em Agosto, esta medida foi ampliada aos abandonados até três anos, passando-se a conceder uma gratificação de $9 \$ 000$ réis, por uma vez somente. A SCML cria que este apoio não representava uma maior despesa, mas sim uma economia, pois caso tivesse de pagar este serviço a uma ama o encargo estender-se-ia por dez anos (AHSCML, Ata ... no 9: 61 e 101; Relatório... 1872: 10).

No mesmo ano, a SCML aplicou medidas que pretendiam acabar com os resquícios de abandono em locais públicos. Neste sentido, "começou por pedir a continuação mais eficaz do auxílio policial” (AHSCML, Relatório... 1872: 6). A mesa administrativa da misericórdia propôs ao governador civil de Lisboa a concessão de prémios de $20 \$ 000$ réis, "a quem auxiliando a autoridade revelasse à polícia os culpados autores de tais delitos. (...) E na verdade a experiência não foi estéril, porque os abandonos não aumentaram". Por contraponto à diminuição do abandono infantil, a SCML revela não ter aumentado o infanticídio e o aborto (AHSCML, Relatório... 1872: 11) ${ }^{11}$.

11 A SCML reconhecia a dificuldade de atuação dos agentes de autoridade dada a inexistência de um registo civil dos nascimentos (AHSCML, Relatório... 1872: 7). 
Outra das preocupações desta instituição, passou por estabelecer um modelo de fiscalização das amas elaborando, para este efeito, o Regulamento para o Serviço de Inspecções.

"Considerando a mesa da Santa Casa da Misericórdia de Lisboa, que grande parte dos expostos sob sua tutela não recebe das amas o conveniente tratamento e educação, como por vezes tem subido ao seu conhecimento por denúncias e queixas, confirmadas posteriormente pelas informações colhidas das autoridades administrativas" (AHSCML, Regulamento... 1873: 3).

Mais tarde, em 1886, a instituição cria o Regulamento da Real Casa dos Expostos. Não se trata de um regulamento sobre o modelo de admissão e/ou acolhimento dos abandonados, mas sim sobre o funcionamento da instituição. Incluí o tipo de funcionários, o seu número e funções (algumas das quais relacionadas com os expostos), bem como algumas disposições gerais. É nestas últimas que se incluem normas de criação dos expostos, nomeadamente, relacionadas com: a sua colocação em bons mestres de ofícios; a entrega de expostas a pessoas de boa moral e conduta para aprendizagem; as emancipações; e, por fim, as normativas em caso de doença (AHSCML, Regulamento... 1886: 44).

No contexto nacional foi apenas em 1888 que se uniformizou e regulamentou a assistência aos expostos, impondo-se o novo modelo a todo o território. "Após um período de indefinições e ambiguidades legislativas" foi aprovado o Regulamento para o serviço dos expostos e menores desvalidos ou abandonados. Nos hospícios podiam ser admitidas crianças: filhas de pais incógnitos que as desampararam; cujos pais haviam desaparecido; que não pudessem ser criadas pelos pais (por morte, prisão, degredo, idade avançada ou doença grave) ou por outro parente (Fonte 2011: 5; Lopes 2016(b): 3).

A administração destes menores ficou a cargo das câmaras municipais até aos sete anos, peródo em que ficavam junto de amas, transitando, a partir de então, para as juntas gerais de distrito. Previa-se que, até aos doze anos, frequentassem asilos-escola (criados pelos municípios em cada sede de concelho), dotados de oficinas próprias para a aprendizagem de ofícios segundo as apetências de género. A responsabilidade das referidas juntas só cessava quando atingiam os dezoito anos, altura em que os expostos se emancipavam (Cubeiro 2011: 12; Fonte 2011: 5; Lopes 2016: 15).

Relativamente aos subsídios de lactação, estipulou-se a duração máxima de doze meses (extensível a dezoito/vinte e quatro por doença). Caso os pais fossem indigentes, viúvos pobres ou perante invalidez do filho, após os sete anos, podiam pedir o internamento da criança, mediante autorização da junta geral de distrito (Cubeiro 2011: 12; Lopes $2016: 15$ ).

Contudo, por dois decretos de 1892 e após fortes críticas, as juntas gerais de distrito foram extintas passando "para o Estado e para as câmaras municipais as res- 
petivas atribuições" e sendo substituídas por comissões distritais. Neste contexto, foi anulada a obrigatoriedade municipal de criação de asilos-escola e a tutela das crianças maiores de sete anos (e até aos dezoito anos ou até poderem desempenhar uma função remunerada) retomou aos municípios (Fonte 2004: 198-199, 2011: 5-6). "Com efeito, as Câmaras Municipais voltaram a reassumir integralmente o processo de criação (... ) com a contrapartida de um subsídio do Estado, proporcional ao número de menores que para elas fossem transferidos". Este sistema só se revelou viável, pois o número de expostos apresentava uma tendência decrescente (Fonte 2011:6) ${ }^{12}$.

Não obstante o encerramento da roda dos expostos na capital, a nova regulamentação e a diminuição do abandono infantil, em inícios do século XX a Misericórdia de Lisboa continuava-se a queixar do excessivo número de crianças à sua tutela. Em 1908, menciona-se o "avultado número de expostos menores de 14 anos que se encontram no edifício (...) faltando acomodações próprias para eles dormirem" (AHSCML, Ata ... no 17, fl. 176-176v). Em parte, por este motivo, em 1910 foi elevado o vencimento das amas de leite, uma vez que eram entregues na instituição bastantes crianças em idade de amamentação (AHSCML, Ata ... n. ${ }^{\circ}$ 17, fl. 283-283v).

Apesar da diminuição, no ano económico de 1900-1901 a Misericórdia de Lisboa tinha à sua tutela 2573 crianças, 237 das quais entradas nesse ano. $\mathrm{O}$ decréscimo do total da população e das entradas na instituição, contrasta com a concessão de subsídios de lactação, sendo que nesse ano foram atribuídas 4962 pensões (AHSCML, Relatório... 1902).

\section{Conclusão}

Oitocentos foi o século da criança, pautado por uma crescente consciencialização da sua importância para o Estado, que a perspetivou como o progresso da Nação, mas também para a família, visando a sua responsabilização e a permanência dos menores junto desta. Este novo ascendente foi igualmente extensível a um grupo particular de crianças - os expostos. Desta forma se justifica, desde o final do século XVIII e ao longo do século XIX, a intervenção do Estado na assistência aos expostos, inicialmente, tentando combater o infanticídio e, mais tarde, o próprio abandono infantil.

$\mathrm{O}$ modelo vigente durante as primeiras 60 décadas de Oitocentos, assente na legalidade da exposição anónima, levou a abusos desta prática e consequentes reflexos na qualidade de vida destes menores. O debate público tornou-o evidente, demonstrando a necessidade de mudança desde meados do século. As soluções

12 Quanto aos subsídios de lactação, estes passaram a ser pagos trimestralmente às amas, após inspeção (Fonte 2011:6). 
então propostas por médios, políticos e intelectuais, apoiadas pela própria Misericórdia de Lisboa, viriam, em 1867, a contar com a intervenção governamental nesta calamidade pública. O encerramento da roda dos expostos e, com ele, do caráter legal que o abandono anónimo tinha tido até então, visava "tornar o processo de admissão mais transparente, evitando os sucessivos abusos e irregularidades, sem que daí resultassem os esperados ganhos populacionais" (Fonte 2011: 2-3). O mote foi a responsabilização parental. Só mediante a ausência de recursos dos pais interviria a sociedade, passando a representar um encargo da comunidade.

Os reflexos desta transição foram notórios na capital - uma grande diminuição do número de crianças entregues na Real Casa dos Expostos de Lisboa, contrastando com um aumento do número de subsídios de lactação concedidos e não havendo, por contraponto, um acréscimo dos infanticídios. Tal transmite-nos uma crescente consciencialização do abuso face ao mecanismo da roda dos expostos, bem como uma preocupação para com a manutenção dos menores no seu seio familiar.

Para além da SCML ter aplicado o modelo tendencialmente seguido no reino, procurou ainda adaptar as suas medidas à realidade da grande capital, levando a cabo alguns particularismos como são exemplo o pagamento a polícias para descoberta dos pais expositores ou a regulamentação das fiscalizações. Efetivamente, esta instituição demonstrava não só uma grande preocupação na diminuição do abandono, como também no acompanhamento e bom tratamento daqueles que se encontravam à sua tutela, importando a sua criação, alimentação, educação, ... em suma, o seu bem-estar e integração social.

Não obstante, alguns elementos do antigo modelo de assistência aos expostos persistiram. Por exemplo, mesmo após o encerramento da roda dos expostos na capital continuou-se a utilizar a denominação Real Casa dos Expostos de Lisboa ou Hospital dos Expostos, mantendo o local onde os mesmos eram entregues o nome de "roda". Também estas crianças levariam para sempre consigo a nomenclatura "exposto".

\section{Fontes e Bibliografia}

\section{Fontes manuscritas}

Arquivo Histórico da Assembleia da República [AHAR]

Debates parlamentares da Câmara dos Senhores Deputados (disponíveis em http:// debates.parlamento.pt/?pid=mc) - 1855 (ata n.o 13) e 1858 (ata n. $\left.{ }^{\circ} 2\right)$.

Arquivo Histórico da Santa Casa da Misericórdia de Lisboa [AHSCML]

Fundo Santa Casa da Misericórdia de Lisboa, Secção Criação dos Expostos (CE)

Correspondência, Cx. 13, Mç. 13, Proc. 1, 11 de Setembro de 1853.

Livros de atas da mesa da administração n.o 2 (1853), 3 (1853), 9 (1871-1873) e 17 (1904-1910).

Relatórios da mesa da Santa Casa da Misericórdia de Lisboa, 1836-1910. 


\section{Fontes impressas}

(1870). “Decreto de 14 de Janeiro de 1868”, Collecção Official da Legislação Portugueza. Anno de 1869. Lisboa: Imprensa Nacional.

(1837). "Decreto de 19 de Setembro de 1836", Collecção de Leis e de Decretos e outras Providencias Regulamentares, desde 16 até 30 de Setembro. Lisboa: Imprensa Nacional.

(1868). “Decreto de 21 de Novembro de 1867”, Collecção Official de Legislação Portugueza, anno de 1867. Lisboa: Imprensa Nacional.

CUNHA, Manuel Caetano da (1873). Breves considerações sobre as rodas dos expostos. Porto: Typographia Franceza e Nacional.

(1862). “Ofício da Intendência Geral da Polícia, de 5 de Junho de 1800”, Resoluções do Conselho de Estado na secção do contencioso administrativo, coligidas e explicadas por José Silvestre Ribeiro, Tomo X. Lisboa: Imprensa Nacional.

(1862). “Ordem Circular da Intendência Geral da Polícia, de 24 de Maio de 1783”, Resoluções do Conselho de Estado na secção do contencioso administrativo, coligidas e explicadas por José Silvestre Ribeiro, Tomo X. Lisboa: Imprensa Nacional.

RIO MAIOR, Conde de (1869). As finanças e a mortalidade dos expostos da Santa Casa da Misericórdia de Lisboa. Lisboa: Imprensa Nacional.

RIO MAIOR, Conde de (1866). Uma opinião sobre os expostos da Santa Casa da Misericórdia de Lisboa. Lisboa: Imprensa Nacional.

SANTA CASA DA MISERICÓRDIA DE LISBOA (1886). Regulamento da Real Casa dos Expostos, Lisboa. Lisboa: Imprensa Democrática.

SANTA CASA DA MISERICÓRDIA DE LISBOA (1873). Regulamento para o Serviço de Inspecções. Lisboa: Typographia do Futuro.

VAZ, Francisco de Assis (1843). Algumas considerações sobre expostos: fragmento da obra do barão de Gerando. Trad. F. D’Assis e Souza Vaz. Porto: Typ. da Revista.

\section{Periódicos}

Diário de Notícias, 6 Ano, No 1 772, 3 de Dezembro de 1870.

CARVALHO, Thomaz (1853). “Abaixo a roda dos expostos”, Revista Universal Lisbonense, 46-48, 543-546, 555-557 e 567-568.

\section{Estudos}

ABREU, Laurinda (2005). "Un destin exceptionnel: les enfants abandonnés au travail (Évora, 1650-1837)”, Annales de Démographie Historique, 2, 165-183.

ANTUNES, José Damas (2015). Os Expostos da Roda de Lisboa. Percursos de vida na Lourinhã e em Torres Vedras. Séculos XVII-XIX. Lisboa: Edições Colibri.

CUBEIRO, Tiago (2011). A assistência à infância em Torres Novas: estudo dos subsídios de lactação concedidos pela Câmara Municipal (1873-1910). Coimbra: FL-UC.

FONTE, Teodoro (2004). No Limiar da Honra e da Pobreza. A Infância Desvalida e Abandonada no Alto Minho (1698-1924). Braga: ICS-UM. 
FONTE, Teodoro (2011). "República, assistência e protecção social de menores em perigo moral”, Estudos Regionais, II Série, 4. Viana do Castelo: Centro de Estudos Regionais, 173-185 (disponível em http://www.ghp.ics.uminho.pt).

FUCHS, Rachel (1984). Foundlings and child welfare in nineteenth century France. Albany: State University of New York Press.

HUNECKE, Volker (1985). "Les Enfants Trouvés: Contexte Européen et Cas Milanais (XVIII-XIX siècles)", Revue d'Histoire Moderne et Contemporaine, 32, 3-29.

JABLONKA, Ivan (2010). Les enfants de la République. L'integration des jeunes de 1789 à nos jours. Paris : Éditions du Seuil.

KERTZER, David (1993). Sacrified for Honor. Italian Infant Abandonment and the Politics of Reproductive Control. Boston: Beacon Press.

LOPES, Maria Antónia (2016-b). “Assistência à infância após a extinção da Roda dos Expostos: Hospício dos Abandonados e crianças maiores de sete anos (distrito de Coimbra, 1872-1890)", Da caridade à solidariedade: políticas públicas e práticas particulares no mundo ibérico. Braga: Universidade do Minho/Lab2PT, 173-191 (disponível em https://www.academia.edu/).

LOPES, Maria Antónia (2002). “Crianças e jovens em risco nos séculos XVIII e XIX. O caso português no contexto europeu”, Revista de História da Sociedade e da Cultura, 2, 155184 (disponível em https://estudogeral.sib.uc.pt/handle/10316/25021).

LOPES, Maria Antónia (2016). “Mães solteiras entre a repressão e os apoios do Estado: intimações, subsídios e abandonos no distrito de Coimbra, 1850-1890", Do silêncio à ribalta. Os resgatados das margens da História (séculos XVI-XIX). S.l.: Lab2PT, 37-54 (disponível em https://www.academia.edu/).

LOPES, Maria Antónia (2013). “Os socorros públicos em Portugal, primeiras manifestações de um Estado-Providência (séculos XVI-XIX)”, Estudos do Século XX, 13, 257-280 (disponível em https://www.academia.edu/).

PÉREZ MOREDA, Vicente coord. (1995). Expostos e ilegítimos na realidade ibérica do século XVI ao presente. Actas do III Congresso de ADEH (Associação Ibérica de Demografia Histórica), vol. 3. Porto: Edições Afrontamento.

PÉREZ MOREDA, Vicente (2005). "La infância abandonada en España (siglos XVI-XX). Discurso de ingresso en la Real Academia de la Historia (8 de mayo de 2005)”, Mensajeros de la paz. Madrid, 14.

REIS, Maria José (1993). Crianças abandonadas e expostas no Concelho de Alenquer (1866-1871). Lisboa: Faculdade de Ciências Sociais e Humanas da Universidade Nova de Lisboa.

REVUELTA EUGERCIOS, Bárbara (2011). Los usos de la inclusa de Madrid, mortalidade y retorno a princípios del siglo XX (1890-1935). Madrid: Universidad Complutense de Madrid.

SÁ, Isabel dos Guimarães (1995). A circulação de crianças na Europa do Sul: o caso dos expostos do Porto no século XVIII. Lisboa: F.C.G. e JNICT.

SÁ, Isabel dos Guimarães (1992). "Abandono de crianças, infanticídio e aborto na sociedade portuguesa tradicional através das fontes jurídicas", Penélope, 8, 75-89.

SANTA CASA DA MISERICÓRDIA DE LISBOA (1998). Inventário da criação dos expostos do Arquivo Histórico da Santa Casa da Misericórdia de Lisboa. Lisboa: SCML. 